\title{
El pensamiento utópico y las críticas de Popper, Molnar y Marcuse
}

\section{Utopian thought and the criticism of Popper, Molnar and Marcuse}

\author{
Lucas E. Misseri* \\ Centro de Investigaciones Jurídicas y Sociales, \\ Universidad Nacional de Córdoba, Córdoba, Argentina \\ ORCID: https://orcid.org/o0oo-0002-8I49-I90X \\ ISSN: ISSN-OI85-4259; e-ISSN: 2007-9176 \\ DoI: http://dx.doi.org/10.28928/revistaiztapalapa/782015/aot3/misseriel
}

\section{Resumen}

A partir del análisis conceptual del término "pensamiento utópico" y su distinción de las utopías particulares se procura desarticular tres críticas diferentes realizadas a esa forma de pensar. En primer lugar, la crítica liberal con visos psicologistas de Karl Popper. En segundo lugar, la crítica conservadora con visos teológicos de Thomas Molnar. En tercer y último lugar, la crítica neomarxista con visos historicistas de Herbert Marcuse. La tesis aquí defendida es que las tres críticas fallan por confundir las características de utopías históricas particulares con la facultad de pensar utopías.

Palabras clave: utopismo, antiutopismo, liberalismo, conservadurismo, neomarxismo

\footnotetext{
Abstract

Starting from the conceptual analysis of the term "Utopian thinking" and its distinction from particular utopias it is sought to dismantle three different criticisms made to that mindset. First, the liberal criticism with psychologist overtones of Karl Popper. Secondly, the conservative criticism with theological overtones of Thomas Molnar. Third and finally, the neo-Marxist criticism with historicist overtones of Herbert Marcuse. The thesis stated here is that the three criticisms fail by confusing the characteristics of particular historical utopias with the ability to think utopias.

Key words: Utopianism, Anti-Utopianism, Liberalism, Conservatism, Neo-Marxism.
}

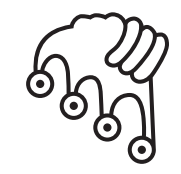

\section{IZTAPALAPA}

Agua sobre lajas

Doctor en Filosofía por la Universidad Nacional de Lanús. Becario posdoctoral del Consejo Nacional de Investigaciones Científicas y Tecnológicas. Miembro del grupo de investigaciones sobre Ética y Filosofía Política "DEep". lucmisseri@gmail.com 
pensamiento utópico ha tenido hasta el momento una prolífica historia con momentos de mayor producción de utopías como la Grecia clásica, el Renacimiento, la Ilustración y su estudio tuvo un pico a fines de la década de 1960 en el contexto de la Guerra Fría en el que dos cosmovisiones sociopolíticas se enfrentaban globalmente. Con la desaparición de la polaridad a partir de la desintegración de la Unión Soviética y el desmembramiento de los países de su esfera de influencia se habló de fin de la historia y sobre todo de fin de las utopías. Las dos guerras mundiales habían inclinado el pensamiento utópico a prevenir males más que a proponer sociedades ideales como atestiguan los trabajos ampliamente difundidos de H. G. Wells y sus principales emuladores: E. Zamyatin, A. L. Huxley y G. Orwell. ${ }^{1}$ En las siguientes páginas se procura mostrar que ese giro hacia las distopías constituye una forma más de pensamiento utópico tendiente a imaginar sociedades peores que las contemporáneas a fin de evitar los males venideros. Es lo que algunos autores llaman utopismo crítico (Moylan, 2000) y que se manifestó a principios del siglo xx cuando H. G. Wells escribió su "utopía moderna" como una utopía crítica de las utopías clásicas pero aún dentro de esa tradición de pensamiento cuyo primer pilar fuera la República de Platón y el origen del término la obra de Tomás Moro.

Se distingue en nuestra investigación el distopismo del antiutopismo, es decir, la proyección de escenarios negativos futuros para mejorar la sociedad actual — distopías- del rechazo del beneficio de esa forma de pensar en pos de una defensa de la tradición o de una metodología fragmentaria de mejora social — antiutopismo-. Para sostener esta tesis se eligieron tres críticas antiutópicas de diverso origen y con finalidades distintas. Estos son, en primer lugar, la crítica de Karl Popper cuyo prestigio en el campo de la epistemología muchas veces es exportado infructuosamente al de la política. En segundo lugar, la crítica de Thomas Molnar, quien expone los

I Tanto Zamyatin como Huxley y Orwell reconocieron su deuda con Wells, siendo Orwell el más crítico quien llamaba a una suerte de "parricidio" literario para dejar de lado el fuerte influjo wellsiano que marcaba a su generación (Orwell, 1946:83-88). 
reparos de la ortodoxia religiosa ante el pensamiento utópico pero no meramente desde un posicionamiento político sino con argumentos teológicos. En tercer lugar, la crítica de un pensador neomarxista cuya obra es considerada utópica, Herbert Marcuse, quien en una conferencia en torno al final de la utopía pone en juego las contradicciones del marxismo con el utopismo que se remontan a sus orígenes con la obra de Engels.

El objetivo es mostrar a partir de una aclaración conceptual de qué se entiende por utopía y pensamiento utópico que las tres críticas no invalidan el pensamiento utópico sino que confunden los mismos conceptos desde perspectivas muy disímiles. Se intenta mostrar que el error que llevó a finales del siglo xx a hablar de una clausura del pensamiento utópico tiene que ver con el hecho de extender las ideas de utopías particulares geográfica y temporalmente situadas a una forma de pensamiento que es de por sí atemporal y que puede ser pensada como una necesidad de mejora constante de la sociedad. El prestigio de Popper, Molnar y Marcuse hace que sus críticas se repitan en el siglo xxI sin prestar atención al renacimiento experimentado por el pensamiento utópico desde finales del siglo pasado con la revolución tecnológica que supuso la informática y el ciberespacio. Probar la importancia del pensamiento utópico es algo que excede la intención de este artículo, se limita el alcance del trabajo a exponer que tres de sus más importantes críticas son débiles y que no son suficientes para invalidar toda una forma de pensamiento.

\section{Algunas precisiones entorno al pensamiento utópico}

En su libro de 1972, L'Avenir du Passé: Utopie et Litterature construido a partir de un seminario que Alexandru Cioranescu dio en Argentina, ${ }^{2}$ el autor ofrece una lista de los principales sentidos de la palabra "utopía". Cioranescu inicia su análisis con base en el Diccionario de la Lengua Francesa y le añade dos sentidos más para hacer justicia a las tendencias teóricas, propias de la que podríamos llamar teoría de la utopía, que eran populares en los entornos académicos de finales de la década de 1960. Elegimos esta obra del especialista en literatura comparada de origen rumano por el impacto que tuvo en los estudios utópicos de finales del siglo $\mathrm{xx}$, influyendo

2 Cioranescu cuenta en el libro que este surgió de su seminario dictado en la Universidad Nacional del Sur, en Bahía Blanca, provincia de Buenos Aires, Argentina. Extrañamente, el libro aún carece de traducción al castellano. 
en notables teóricos de la utopía como Bronislaw Baczko, Raymond Trousson y Jean Servier. ${ }^{3}$ Dice Cioranescu:

En efecto, los diccionarios se han equivocado al detenerse en los tres significados que venimos a enumerar: [I] obra de Moro, [II] género literario, [III] proyecto irrealizable. La palabra ha proseguido su evolución y son necesarias dos nuevas definiciones. Hay un cuarto significado que busca que el nombre utopía convenga a [IV] toda "orientación que trasciende la realidad y que, al mismo tiempo, rompe los vínculos del orden existente". [...] El quinto y último significado que se halla para esta palabra es también reciente y también universalmente aceptado: se acomoda preferentemente al uso adjetivado y de la expresión consagrada, [V] “método utópico” (Cioranescu, 1972:2I).

El primer significado que da el diccionario francés consultado por Cioranescu es un nombre propio, y por ello, no conlleva mayores dificultades de análisis. "Utopía" es una referencia abreviada del Librito áureo no menos saludable que festivo sobre la óptima república de la nueva isla de Utopía ${ }^{4}$ del escritor y político inglés Tomás Moro, escrito y publicado en Lovaina, Países Bajos, en lengua neolatina. Los problemas teóricos surgen cuando los investigadores deciden entrecruzar este primer sentido con los otros mencionados y preguntarse, por ejemplo: si la obra de Moro, nacida del diálogo de humanistas, es meramente un proyecto imposible e irrealizable o una sátira social con el único fin de entretenerse con bromas eruditas en griego e imitaciones de los clásicos grecolatinos.

El segundo significado es el preferido por Cioranescu. En este caso, la utopía además de un libro es un género literario con características específicas que lo diferencian de otros géneros. Cioranescu considera que este es el significado estricto de la palabra y que los otros no son más que meras extensiones. Por eso, tal como repite su discípulo Trousson, como veremos más adelante, desde el enfoque literario se considera que puede hablarse de utopía en sentido estricto y utopía en sentido amplio. Son utopías en sentido estricto aquellos textos que pueden ser clasificados en un género literario concreto por cuestiones formales, ${ }^{5}$ mientras que todos los

3 Me refiero a Les imaginaires sociaux, 1984, de Baczko; Voyages aux pays de nulle part, 1975, de Trousson; y L'Utopie, 1979. Los tres traducidos al castellano en los años posteriores y que influirían también en el enfoque hispanoamericano.

4 En el original latino Libellus vere aureus nec minus salutaris quam festives de optima reipublica statu deque nova insula Utopia.

5 Entre esas características pueden enumerarse un relato enmarcado en un diálogo entre un viajero y una persona que desconoce la utopía. En ese diálogo el protagonista describe las bondades de la 
otros significados de utopía son considerados en el sentido amplio o lato del término. Es este último sentido el que consideraremos aquí la referencia del término "pensamiento utópico" y de su sinónimo "utopismo" entendido como la capacidad humana de generar utopías.

El tercer significado al que alude Cioranescu es el pensar a la utopía como un "proyecto imposible" o una "quimera". Este es uno de los más cercanos a lo que se puede llamar el sentido "coloquial" del término, siendo un remanente de la obra de la crítica marxista al utopismo y que ha sido retomado por pensadores contemporáneos como Herbert Marcuse en sus conferencias de 1967 reunidas bajo el sugerente título de El final de la utopía. Como se expondrá más adelante, el francfortiano afirma en esas conferencias que el final de la utopía ha llegado, puesto que lo que hasta ese momento era considerado irrealizable devino realizable. Él entiende que: "El concepto de utopía es un concepto histórico. Se refiere a los proyectos de transformación social que se consideran imposibles" (Marcuse, 1986:8). No obstante, es evidente que dicha aserción implica entender la utopía de un modo más amplio que como una obra literaria. Marcuse menciona el término "proyecto", término que Cioranescu y Louis Marin ${ }^{6}$ le negarán a la utopía, por lo menos a las obras que inician el género (Cioranescu, 1972:190). En adición a lo anterior, podemos decir que, desde muy temprano, se ha asociado el término "utopía" a la noción de posibilidad. Raymond Ruyer, psicólogo francés y fuerte crítico de la utopía, la definió como un "ejercicio mental sobre los posibles laterales" (Cioranescu, 1972:26). Del mismo modo, el teórico uruguayo Fernando Aínsa afirma que:"La utopía no se limita a ser la construcción imaginaria de un mundo posible, sino que es una forma de percibir y analizar la realidad contemporánea" (Aínsa, 1999:50). De este modo, además de la noción de pensamiento en torno a los mundos posibles o "posibles laterales", Aínsa distingue otra función: la crítica. Algo similar expresa Graciela Fernández cuando, en su estudio del concepto, extrae las dos características que ella considera esenciales de la utopía: la crítica y la ficción (Fernández, 2005:40-4I). Al tiempo que asume la existencia de cuatro modelos utópicos: I. posible/deseable; 2. posible/indeseable; 3. imposible/indeseable; y 4. imposible/deseable (Fernández, 2005:42). La filósofa

utopía al contrastarlas con las debilidades la sociedad contemporánea del autor utópico. La insularidad o el aislamiento suelen ser también características de la utopía clásica, junto con la figura de un fundador mítico que estableció el orden utópico en una comunidad (cf., Cioranescu, 1972; Trousson, 1995).

6 Louis Marin, autor de La utopía, juegos de espacio, sostiene la teoría de que el utopismo es ideológicamente neutral. Esta idea puede ser cuestionada desde análisis contemporáneos como el de $\mathrm{P}$. Ricoeur, tal como veremos posteriormente. 
argentina considera que algunas ficciones utópicas pueden ser posibles, e incluso es deseable que lo sean. La misma defensa de la posibilidad de la utopía se encuentra en otro escrito contemporáneo: Utopía de Vittor Ivo Comparato. Ahí el pensador italiano afirma que el término en cuestión constituye un "modelo de una comunidad política perfecta que, sin embargo, no existe [lo que] no implica para el escritor [que la concibe] la noción de imposibilidad" (Comparato, 2006:9).

El cuarto significado de "utopía" que destaca Cioranescu está tomado literalmente de la obra Ideología y utopía (1929) de Karl Mannheim. La idea de la utopía como negación de lo "real" es un tópico dentro de la teoría de la utopía, sin embargo, se discrepa en cuanto a su alcance y finalidad. Para autores como George Kateb "la utopía es la 'negación de la negación' [... ] lo opuesto al mundo real” (Kateb, 1982:292). Para Aínsa: "La utopía es siempre dualista en tanto concibe y proyecta una contra-imagen cualitativamente diferente de las dimensiones espacio-temporales del presente" (Aínsa, 1999:37). Así, observamos cómo la negación del statu quo que subyace a la crítica utópica se manifiesta en lo que Aínsa llama una "contra-imagen", esto es, en la descripción fictiva que conlleva toda utopía. Esta negación se ve exacerbada cuando Mannheim establece que:

Un estado de espíritu es utópico cuando resulta desproporcionado con respecto a la realidad dentro de la cual tiene lugar $[\ldots]$ se orienta hacia objetos que no existen en la situación real [...] llamaremos utópicas a aquellas orientaciones que trasciendan la realidad y que, al informar la conducta humana, tiendan a destruir parcial o totalmente, el orden de cosas predominante en aquel momento (Mannheim, 1966:260-26I).

Aquí la noción de utopía ya no puede ser identificada con los sentidos (I) y (II), puesto que trasciende la mera literalidad y deviene en un concepto extremadamente abarcador. Esto le permite a Mannheim englobar bajo su significación periodos históricos y conjuntos de ideas tan disímiles como: el milenarismo anabaptista, la idea humanitaria liberal, la idea conservadora y lo que él denomina la "utopía socialista-comunista” (Mannheim, 1966:282-313). La utopía en este sentido se confunde con otros géneros literarios e imaginarios sociales a los que está asociada tales como el milenario, pero con los cuales, al entender de muchos teóricos, no debería identificarse (Davis, 1985; Trousson, 1995).

Por último, podemos pensar que Tomás Moro se vale de un método inaugurado por Platón que ha seguido presente hasta nuestros días, al punto de que algunos autores sostienen que es constitutivo de nuestro pensar racional $(\mathrm{V})$. Este quinto sentido amplio del término utopía sería mejor explicitado con el término pensa- 
miento utópico, puesto que, como dijimos, la utopía en sentido estricto, para Cioranescu, está en las obras que pertenecen al género utópico y no al método de su construcción. En este sentido llamar utopía al pensamiento utópico es un caso de metonimia infelizmente muy popularizado en contextos académicos. Cioranescu atribuye este quinto sentido al filósofo André Lalande y lo encuentra también, en las obras de sociólogos como Claude Dubois, Georges Duveau y Hans-Jürgen Krysmanski. ${ }^{7}$ Krishan Kumar también incluye a H. G. Wells, quien escribió que la sociología no era una ciencia exacta sino una forma moderna de pensamiento utópico (Kumar, 1990:197). Esta también puede pensarse desde los conceptos de función utópica, tal como aparecen en Ernst Bloch y en la obra del filósofo argentino Arturo Roig, aunque desde fundamentaciones diversas. Para Bloch hay una función utópica propia de la literatura y el arte que tiene que ver con el hecho de obtener una suerte de "pre-aparición" o "ilusión anticipatoria", Vorschein, que convierta lo "aún-no-devenido", nicht-noch-geworden, en la realización del anhelado "hogar", Heimat (Bloch, E. 1988:xxxiii). Mientras que para Roig se trata de una función discursiva que tiene el objeto de llevar a cabo transformaciones a partir de cuatro subfunciones: la función crítico-reguladora; la función liberadora del determinismo legal; la función anticipadora del futuro; y la función de ruptura con la temporalidad mítica (Roig, 1987:21-22).

Es esta última definición o sentido amplio del término utopía el que aquí me interesa y que considero es el más filosófico y perenne de la utopía. El cual aún no ha sido derrotado por las críticas que expondré más adelante. Para evitar malos entendidos que abundan tomo la expresión acuñada por Frank Edward Manuel "pensamiento utópico" y la hago sinónima de "utopismo" y "utopía en sentido amplio", términos empleados por Cioranescu y Trousson, respectivamente. El pensamiento utópico, según este sentido general del término utopía, está en sí vacío de contenido sustantivo. Este le viene dado por las condiciones sociohistóricas de cada época y de los sujetos que anticipan la posibilidad de algo distinto a lo actual, que colme la falta, la eterna necesidad humana. En este sentido tanto Bloch como Adorno coinciden en que la utopía es la antítesis de la muerte y que al mismo tiempo necesita de ella para oponérsele. El pensamiento utópico es la oposición a lo perecedero de lo humano, es la esperanza de redención (Bloch, 1988) o, en términos de Wells, es el esfuerzo ético contra la entropía social (Wells, 1905). En este mismo espectro

7 Los textos citados por Cioranescu son: Lalande, A. Vocabulaire technique et critique de la philosophie, 1923; Dubois, C. Problèmes de l'utopie, 1968; Duveau, G. Sociologie de l'utopie, 1961, y Krysmanski, H.-J., Die utopische Methode, 1963. 
podría incluirse la tesis de utopía-marco de Robert Nozick, según la cual la única utopía válida sería aquella que permita convivir con los anhelos de los otros en un cierto equilibrio (Nozick, 1991:287). El pensamiento utópico toma forma de un método de transformación social que tiene su raíz en el discurso pero que no se limita a él, sino que se expande hacia la praxis social. Seyla Benhabib mostró, en sus estudios sobre la Escuela de Fráncfort, cómo la crítica social ya no necesita la utopía y que de la racionalidad utópica crítica se pasó a la racionalidad comunicativa (Benhabib, 1986:223). Sin embargo, el propio Karl-Otto Apel, quien contribuyó con su intercambio con Habermas al afianzamiento de ese tipo de racionalidad, reconoció que en este sentido amplio de la utopía la ética discursiva es afín a esta forma de pensamiento (Apel, 1986).

Asimismo, en este sentido el pensamiento utópico presupone no solo una crítica de la sociedad contemporánea sino también una crítica de las utopías anteriores. Para ello pueden clasificarse las utopías en variadas tipologías; en mi investigación he podido reconocer por lo menos cuatro tipos: las utopías literarias elaboradas generalmente en forma de novelas y que tienen la tarea de hacer explícito lo aúnno-consciente (noch-nicht-bewusst) que oculta la ideología de cada lugar y tiempo determinados. En segundo lugar, las utopías programáticas, aquellas que buscan establecer principios adecuados a las necesidades sociales del presente a partir de tratados que estimulen la realización del tercer tipo de utopías: las prácticas. Estas son comunidades intencionales establecidas a partir de ciertos principios rectores que intentan modificar su realidad a partir de la construcción de una sociedad empírica modelo. Por último, las utopías que en otro lado denominé instrumentales y que también podrían ser llamadas "estéticas" en sentido amplio del término, en tanto que promueven la sensibilidad ante la fragmentación social y estimulan la creación esperanzadora de alternativas.

Todas estas distintas utopías comparten dos grandes supuestos que tiene que derrotar un antiutópico para dar argumentos suficientes para desestimar esta forma de pensamiento. El primer supuesto radica en la creencia de la posibilidad del ser humano de ejercer un cambio sustantivo capaz de transformar su entorno a partir de la voluntad mediante el trabajo individual y grupal. En este sentido choca con las teorías que ensalzan la preeminencia del azar y las que defienden cualquier forma de fatalismo. Es cierto que esto marca un cierto pathos optimista de los utópicos (Fernández, 2005); sin embargo, el optimismo de los utopistas puede estar puesto en una visión nostálgica de un pasado al que se quiere regresar - protoutopías antiguas-; en el presente, como un lugar alternativo del que se habita en el que se realiza en acto el ideal buscado — utopía renacentista—; o por último, en el futuro, 
tanto en el mismo lugar como en otro, aunque generalmente en todo el orbe -utopía moderna-. Esta parece ser la tendencia generalizada, aunque nuestro tiempo condena el término "utopía" a la categoría de insulto por lo cual ha sido reemplazado por alternativas como "ciencia ficción" (Bloch, 1988:2) o los de "eucronía" o "eupsiquía” (Manuel y Manuel, 1997:4). ${ }^{8}$ El segundo supuesto es que esa intervención es deseable y necesaria. En otros términos, que los seres humanos merecemos vivir del mejor modo en cada una de las distintas etapas de nuestra historia, buscando garantizar no solo la supervivencia de la especie (Jonas, 1995:40) sino la buena vida, siendo el concepto de bueno redefinido en relación con los recursos y posibilidades de cada época.

\section{La crítica liberal de Popper}

En su artículo "Utopía y violencia”, que data de 1947, Popper sostiene una línea de fuerte corte liberal que ya había explicitado en La sociedad abierta y sus enemigos, 1945. En esta ocasión define el pensamiento utópico como un "racionalismo erróneo", esto es, viciado, que comprende la acción racional como aquella que dispone de una forma eficaz de los medios para alcanzar fines en futuros remotos.

Considero a lo que llamo utopismo una teoría atrayente, y hasta enormemente atrayente; pero también la considero peligrosa y perniciosa. Creo que es autofrustrante y que conduce a la violencia. / El hecho de que sea autofrustrante se vincula con el hecho de que es imposible determinar fines científicamente. No hay ninguna manera científica de elegir entre dos fines (Popper, 1991:429).

De aquí se sigue que Popper entiende por pensamiento utópico la demarcación de un fin político - el Estado ideal — al cual debe amoldarse el Estado actual independientemente de si para ello es necesario el sacrificio de generaciones, e incluso de la racionalidad misma, convirtiéndola en un mero instrumento de poder. Para el filósofo austriaco, el carácter autofrustrante de esta forma de pensar radica en que el pensador utópico no es un verdadero racionalista, sino que toma la postura del profeta y carece de la humildad necesaria en cualquier contexto epistémico. Para

8 El matrimonio Manuel toma estos neologismos de Ch. Renouvier y A. Maslow; sin embargo, los emplea para explicar las transformaciones del pensamiento utópico desde las utopías de la felicidad perfecta típicas del Renacimiento (eutopías), las utopias de final abierto propias de la Modernidad (eucronías) y las utopías del estado ideal de conciencia (eupsiquías). 
Popper el pensador utópico deja de considerar la posibilidad de estar equivocado y, careciendo de esa humildad intelectual que tiene un propósito no solo moral sino también metodológico, se cree con el derecho de abolir toda crítica e incluso la libertad de expresión. Esto conduce a este tipo de pensadores, continúa, a establecer gobiernos tiránicos y totalitarios. En términos de Isaiah Berlin, puede decirse que Popper asume que en aras de garantizar la libertad positiva - esto es, la libertad para hacer ciertas cosas y disfrutar de ciertas oportunidades-, los pensadores utópicos anulan la libertad negativa - libertad de coacción, de interferencia en los asuntos íntimos de cada individuo (Berlin, 1986) - . Popper no se contenta con la crítica destructiva sino que procura ofrecer una alternativa para la preocupación social que podría mover al pensador utópico sincero: propone atender los problemas inmediatos dejando de lado los fines históricos en lo que él denomina ingeniería gradual o fragmentada (piecemeal engineering). Cree que gradualmente se pueden ir solucionando uno a uno los problemas sociales y mejorar el estado en el que vive toda la humanidad, sobre todo confiando en la acción de organismos internacionales. Medio siglo después de su escrito se puede especular que tal vez esa era su utopía.

Roger Paden reconstruyó la argumentación destacando sus debilidades en su artículo "El antiutopismo de Popper y el concepto de sociedad abierta". Paden inicia el escrito dando una definición de utopismo y dos "axiomas" para el pensamiento político. Define al pensamiento utópico como "el uso de una concepción detallada y concreta de una sociedad ideal como fundamento del pensamiento político" (Paden, 2000:409). En cuanto a los axiomas, aunque Paden no los llama así, son presentados como tales porque no son cuestionados en todo el texto, son considerados evidentes e innecesarios de ser justificados. El primero afirma que el liberalismo necesita el pensamiento utópico, el segundo va más lejos al decir que la filosofía política necesita tener, por lo menos, un momento utópico (Paden, 2000). Estos "axiomas" pueden ser cuestionados desde diversas ópticas, pero, en rasgos generales se puede decir que ambos son el resultado de la definición que ofrece Paden, que se condice con la definición que he dado más arriba de pensamiento utópico según la cual este es un método de abordaje de problemas sociales que implica un desarrollo discursivo en el cual lo utópico se manifiesta como la búsqueda de soluciones creativas racionales a esos problemas. Sin embargo, esto no quiere decir, como creyó Popper, la implantación de un tirano utópico al estilo renacentista, sino que ese mismo método se adecua a distintas necesidades y recursos sociohistóricos abriéndose a los procesos democráticos y dialógicos. Es por ello que algunos autores ven en la defensa de los derechos humanos la única utopía “realista”, generando un interesante oxímoron que une la idea de dignidad y derecho natural de Bloch al tiempo que intenta separarse 
de las imágenes utópicas del pasado reciente: "Los derechos humanos constituyen una utopía realista en la medida en que no proponen más imágenes engañosas de una utopía social que promete la felicidad colectiva, sino que fundan el ideal de una sociedad justa en las instituciones de los estados constitucionales" (Habermas, 2010:19).

La reconstrucción argumental del texto de Popper que hace Paden se centra en ciertas dicotomías sostenidas por el primero: ingeniería gradual / ingeniería utópica, moral / episteme, sociedad cerrada / sociedad abierta, racionalismo crítico / pseudo-racionalismo. A la luz de estas oposiciones, destaca dos críticas principales que Popper hace al pensamiento utópico: por un lado, una crítica moral, y por el otro, una crítica epistemológica. Paden no piensa que la crítica de Popper sea infructuosa; no obstante, cree que algunos de sus argumentos son débiles. Sobre todo el que interesa en este trabajo y que es el que sustenta las dos críticas al utopismo como generador de violencia.

La primera crítica sostiene que la persecución de grandes fines del pensamiento utópico genera violencia. Según Paden, no se sigue de la persecución de grandes o distantes fines la necesidad del ejercicio de la violencia. Un buen ejemplo de esto es el pensamiento de Comenio ${ }^{9}$ quien, pese a escribir toda su vida en pos de una comunidad universal — un paraíso del hombre en el mundo-, jamás aceptó la violencia como un medio para esos fines. La otra crítica que Paden desarticula es la epistemológica. Esta no es solo epistemológica sino también moral, pero se la llama así porque entra en juego el conocimiento y el grado de cientificidad como variables predominantes. Para Popper el pensamiento utópico es pseudoracionalista, precientífico, está al mismo nivel que la creencia en la magia y la reflexión metafísica, no es compatible con la ciencia y es irracional en tanto que supone una postura extremista. El pensamiento utópico tampoco sería contrastable o falsable, dado que no puede hacerse un experimento práctico de su funcionamiento y de sus logros.

En la segunda crítica, se manifiesta un desafío relevante para el utopista, porque lo que hace Popper es cuestionar la noción de autocrítica, ausente en gran parte del corpus utópico, sobre todo en las denominadas "utopías clásicas" ${ }^{\circ 0}$ Para analizar

9 Jan Amos Komensky, latinizado Comenius. Pensador checo, 1592-1670, llamado "el maestro de las naciones" por la importancia de sus aportes en la didáctica. Además de ello fue un teólogo protestante obligado a múltiples exilios en los que propugnó la búsqueda de un saber y un método universales que denominó pansophia. Sus ideales utópicos se entremezclan con ideas quiliastas; pese a sufrir la violencia en varios modos, en su ideal universalista jamás hubo espacio para ella (cf. Manuel y Manuel, 1997:309).

Io Se entiende por utopía clásica las primeras eutopías, aquellas que inauguraron el género: Utopia de Moro, La ciudad del Sol de Campanella, La Nueva Altantida de Bacon, La ciudad feliz de Patrizi... 
esta crítica se prefiere prescindir de las diferenciaciones entre sociedad cerrada / sociedad abierta, porque en parte son anacrónicas; también se prescinde de la diferenciación entre ingeniería gradual / ingeniería utópica porque, como demuestra Paden en su artículo, no suponen ningún progreso conceptual. No obstante, esta idea de que la realización de una utopía no permite la generación de otras utopías, de que el habitante de un Estado ideal no puede ser crítico de su propia sociedad da con el núcleo de la crítica antiutópica del siglo $\mathrm{xx}$-manifestada no solo por teóricos como Popper, Molnar y Marcuse sino por los propios pensadores utópicos

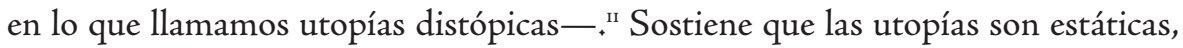
que se presentan como la perfección consumada y que en su falsa felicidad anulan la libertad negativa del individuo. Si bien esta crítica es anacrónica y está colmada de prejuicios liberales, la finalidad de Popper parece ser destacable, puesto que estaría defendiendo el derecho a un utopizar continuo, algo que no sería contradictorio con el pensamiento utópico.

Aquellos que suscriben la creencia de que las utopías no permiten la autocrítica y el cambio, ignoran la evolución del pensamiento utópico; este se ha desarrollado como una tradición que se ha leído a sí misma a partir de un canon de autores y que ha realizado progresos que se legaron a la posteridad. Sería inútil que nos detuviéramos a mostrar cómo aun para Moro, Campanella y Bacon sus tierras imaginarias no eran exactamente la perfección acabada. Baste decir que no se anula el sujeto moral en ellas, es decir, el bien y el mal moral siguen siendo opciones del individuo, y que el paganismo de los habitantes de sus utopías es visto como una imperfección, al tiempo que se esperan nuevos progresos tecnológicos en sus sociedades imaginarias que necesariamente las modificarán. Podemos reconocer que dichas sociedades, por más que presenten esos aspectos de cambio y en un sentido muy laxo de progreso, son de hecho cerradas en el sentido marcado por Popper, en tanto $y$ en cuanto tienden a estar aisladas y a cristalizar un statu quo. No obstante, esas utopías constituyen el intento sesgado de solución a los problemas que suponía la responsabilidad social en su época.

Ejemplos de la historia del pensamiento utópico contradicen a Popper en varias ocasiones. Es suficiente con mencionar a Étienne Cabet y Herbert George Wells, quienes en el siglo xIX y $\mathrm{xx}$ respectivamente, y a diferencia de sus antecesores utópicos, procuraron distanciarse del pensamiento utópico previo sosteniendo

II La lista de autores distópicos es muy amplia y actualmente en el cine hay un boom distópico inspirado en algunos de los textos escritos en el siglo xx. Los más representativos son H. G. Wells, A. L. Huxley, G. Orwell, J. London, E. Zamyatin y R. Bradbury. 
dos aspectos que ellos consideran indispensables para sus utopías y que Popper los toma como características de la sociedad abierta: la democracia y la movilidad social. Puntualmente, en Cabet hay una búsqueda de una democracia tan directa como sea materialmente posible y en Wells hay una contraposición entre la estaticidad de las utopías clásicas y el dinamismo de la utopía moderna que él afirma inaugurar. El utopismo moderno o también crítico se caracteriza así por la posibilidad de disentir, por la aceptación del perfeccionamiento infinito de la propia utopía. Esto último es preanunciado en la noción de "ucronía" acuñada en el siglo xviri, lo que no es otra cosa que la idea de progreso añadida al pensamiento utópico. Con estos dos ejemplos del último cuarto del siglo xix y principios del xx, buscamos mostrar que la crítica de Popper es válida parcialmente y solo se aplica a un conjunto limitado de utopías del siglo XVI y XVII, pero que no es suficiente para cuestionar toda una forma de pensamiento, que en lugar de generar violencia no hace más que poner a la razón al servicio de la humanidad para paliar los males que realmente ejercen una violencia física y simbólica sobre ella a partir de un sentimiento de responsabilidad del que se hacen cargo los pensadores utópicos en cada época que les toca vivir.

\section{La crítica conservadora de Molnar}

El filósofo húngaro Molnár Tamás — nacionalizado estadounidense como Thomas Molnar- escribió en 1967 un libro titulado El utopismo: la herejía perenne, al mismo tiempo que Marcuse dictaba sus conferencias sobre el final de la utopía. Molnar era un pensador conservador católico y admirador de Popper con quien coincide en su dicotomía sociedades abiertas / sociedades cerradas a la que añade la crítica religiosa desde otra dicotomía: ortodoxia / herejía. Su libro tiene como hipótesis central que el utopismo "conduce a la negación de Dios y a la autodivinización esto es, a la herejía" (Molnar, 1970:7).

Para Molnar, a diferencia de Popper, el utopismo constituye una clase especial de mentalidad que se manifiesta recurrentemente en la historia de la humanidad. Su descripción del pensamiento utópico se acerca bastante a la que hicieran Bloch, Cioranescu, Aínsa y Roig, quienes asocian el utopismo a una inclinación natural del hombre. La diferencia está en que esa inclinación natural es una caída, un pecado y no una virtud y un fin deseable como para aquellos: "la mentalidad utópica no se restringe al campo de la planificación política, sino que conforma una categoría de pensamiento autónoma [... ] La inclinación al utopismo es muy intensa en la mente de los hombres y se presenta en casi toda época (Molnar, 1970:II). 
Molnar distingue dos clases de pensadores utópicos: por un lado los historicistas, y por el otro los entusiastas. Los primeros se caracterizan por concebir una filosofía de la historia en la cual la utopía constituye un punto de realización máximo e inevitable. Molnar piensa abiertamente en los marxistas del siglo xx y sus pretensiones de determinismo histórico. Si los primeros tienen una pretensión científica, los segundos tienen una pretensión mística. Este aspecto emparenta al pensamiento utópico con el milenarismo, esto es, con las ideas escatológicas asociadas con un reino de Dios en la Tierra. Pese a la diferencia aparente entre los historicistas y los entusiastas, para Molnar ambos son pensadores religiosos, puesto que buscan oponerse al mal en el mundo. Sin embargo, dice que en su afán generan un nuevo mal: la herética divinización del hombre.

El pensamiento utopista no es simplemente un ejercicio de realización de deseos: antes bien, se trata de un elemento constitutivo de nuestra actitud mental y, como tal, posee su estructura propia $[\ldots]$ este pensamiento utopista es también un mal en sí mismo $[\ldots]$ el utopista es una persona religiosa $[. .$.$] tenemos el derecho de describir al pensa-$ miento utopista como la creencia en un inicio inmaculado y en una perfección alcanzable (Molnar, 1970:13).

Aquí se expresa la similitud ideológica de Popper y Molnar, sobre todo en la repetición de la crítica epistemológica que ya había señalado el filósofo austriaco. Para Molnar el pensador utópico es "simultáneamente irracional y lógico" (Molnar, I970:14). Esta simultaneidad viene a partir de que se proyecta racionalmente una sociedad ideal que dejaría a un lado el aspecto racional de los habitantes de esa utopía, los cuales son concebidos como meras marionetas, autómatas o zombis. Esta crítica de Molnar es digna de ser subrayada porque le aporta a la crítica de Popper un nuevo aspecto: el pensador utópico tendería a cancelar la racionalidad, pero no por frustración como señalaba Popper, sino por anulación de la posibilidad crítica de los ciudadanos en sus proyectadas sociedades ideales. Puede reconocerse que este aporte de Molnar no es más que una consecuencia del concepto popperiano de sociedad cerrada, donde la crítica y la movilidad social no son posibles.

Sin embargo, como se señalaba al principio, esa despersonalización de los habitantes de las sociedades ideales no es el centro de la crítica de Molnar sino el aspecto herético de la tarea del pensador utópico. Para Molnar, "todo pensador utopista trata, en una u otra forma, de cambiar el pensamiento cristiano mismo para justificar así su empresa de reconstrucción psicológica, social y política" (Molnar, 1970:27). Ese es el núcleo de su crítica, el pensamiento utópico atentaría contra el cristianismo, al 
convertirse en su rival, compitiendo con él al prometer el alcance de un "paraíso" en la Tierra. Son muchos los pensadores utópicos que hicieron promesas de ese estilo, un ejemplo de ello es el de Francis Bacon, quien en su Nueva Atlántida piensa en la llegada de un nuevo hombre liberado de los castigos del pecado original, gracias a los beneficios de la técnica moderna. Los neoatlantes tienen un Colegio de los Seis Días donde los herederos del sabio Salomón juegan a ser dioses manipulando cultivos y curando enfermedades. ${ }^{12}$ Otro ejemplo que se puede citar es el del baconiano Jan Amos Comenio, quien en sus textos, principalmente en El laberinto del mundo y el paraíso del corazón, propone la búsqueda de un paraíso inmanente en la Tierra que sirva de preparativo para el paraíso en el Cielo. ${ }^{13}$ Podría considerarse que la inmanencia comeniana alude solo al individuo pero también se manifiesta en instituciones como las que proyecta el checo en su Via Lucis que la onU reivindica como antecedente de su conformación. Molnar tiene bien claro este aspecto cuando afirma que "los escritores utopistas de cierta importancia resultan heréticos desde el punto de vista de la doctrina cristiana, pues tratan de restaurar la inocencia prístina del hombre - su conocimiento y su potencia - $y$, para alcanzar este objetivo, desean anular al pecado original y partir de un comienzo sin mancilla" (Molnar, 1970:28).

Para Molnar los pensadores utópicos han sustituido el milenio cristiano por la idea secular de revolución, pero a su parecer se trataría de la misma inclinación herética. Este aspecto fue advertido también por Emil Cioran en su Historia y utopía cuando, a partir de esta idea de recuperación terrenal del Edén por medio de la voluntad del hombre, el autor rumano lo compara con el pelagianismo tan repudiado por Agustín de Hipona. La gracia divina sería accesible para el utópico. Esto tiene que ver con una particular concepción del hombre que no es casual que se manifieste en el mismo momento en el que Tomás Moro crea el género utópico. Se ve explícitamente en la obra de Giovanni Pico della Mirandola — a la que Moro tuvo acceso $^{14}$ - cuando, probablemente por influjo del hermetismo, reconoce la inesencialidad humana que le permite al hombre devenir bestia o semidiós (Pico della Mirandola, 2008:207-209). Algo similar se manifiesta en Tommaso Campanella

12 Sobre el influjo del pelagianismo en Bacon véase Steven Matthews (2008), Theology and Science in the Thought of Francis Bacon, Ashgate Publisher, Aldershot.

13 Sobre la complementación de las ideas de Paraíso en el Cielo y Paraíso en la Tierra en el pensamiento de Comenio véase Igor Kiss (2009), "The Concept of Paradise as the Theological Starting Point for Comenius' Pedagogy" en Chocholová, S. et al. (ed.), Johannes Amos Comenius. The Legacy to the Culture of Education, Academia, Praga, pp. IO4-III.

I4 Tomás Moro escribió una biografía de Pico della Mirandola titulada "Life of John Picus, Earl of Mirandula" (Moro, 193I:347). 
cuando dice que el hombre es Dios segundo (Campanella, 1954:205-207) y mucho más moderadamente en los poemas de juventud de Tomás Moro donde reconoce que la fama tiene la capacidad de vencer a la muerte (Moro, 1931:334).

En consecuencia, para Molnar "el utopista es, por lo tanto, el gran demoledor de instituciones" (Molnar, 1970:57). No obstante, esta crítica es parcialmente cierta puesto que Moro busca anular el comercio, Bacon las relaciones internacionales, Nozick el Estado proteccionista, Huxley la familia tipo, etc. ${ }^{15}$ También proponen nuevas instituciones que procuran adecuarse de mejor modo a la finalidad de una mejor convivencia y un mejor uso de los recursos. En otras palabras, el utopista demuele para crear nuevas instituciones no para establecer la anarquía, o por lo menos no en todos los casos. El principal inconveniente es que para Molnar la mayoría de los cambios propuestos por los pensadores utópicos suponen lesiones a la institución que él considera sagrada y la única guía para el buen obrar del ser humano: la Iglesia cristiana católica. La pregunta que puede plantearse a Molnar es ¿por qué todos están obligados a aceptar las mismas instituciones que él? En otras palabras, hay un supuesto muy fuerte en la concepción de Molnar que hace difícil la posibilidad de un diálogo en el que se reconozca el derecho del otro, debido a que las dicotomías de corte maniqueo solo dejan dos opciones: o cristiano o hereje. Molnar puede tener razón en que el pensamiento utópico posee un componente herético; ahora bien la pregunta es ¿̇tener una opinión distinta (haeresis) es a priori un error?

Por otro lado, si se lee el texto de Molnar en su contexto histórico se entiende que es una reacción ante la mixtura místico-marxista de Bloch sustanciada en su idea de un principio de esperanza que hace del marxismo una nueva forma de teología secular. Sin embargo, la de Molnar no fue la única reacción, otra fue la de Hans Jonas, quien también destacó la "prometeica arrogancia del ideal utópico" (Jonas, 1995:238), que no es más que la apoteosis del hombre. Jonas capta un matiz propio del utopismo y es su correlación entre el utopista moderno y el titán Prometeo. Marx ya había alabado a esta figura mitológica en sus escritos filosóficos más tempranos:

La motivación atea del materialismo de Marx aparece más claramente en su tesis doctoral. Alli él considera a Epicuro el más grande Aufklärer [ilustrado] de los antiguos porque siguió a Prometeo, "el más noble de todos los mártires en los anales de la filosofía", al desafiar en tanto que hombre mortal a los dioses del cielo y la tierra (Löwith, K. 1949, 47) quía, Estado y Utopía de Nozick; y La Isla de Huxley. 
Por su parte Bloch ensalza a Prometeo no solo por su rol utópico en el mito sino porque el castigo olímpico genera el principio que sostiene el pensamiento utópico mismo: la esperanza (Bloch, 1976:389). Este concepto que constituye una de las virtudes teologales para los cristianos era para los griegos un mal que surgió con el envío de Pandora por Zeus. La esperanza es un mal porque nace de la incertidumbre y como remarcó el propio Bloch si bien tiene una capacidad revolucionaria también puede decepcionar (Bloch, 1988:16). El Schicksal 'destino' es prometheusfeindliche 'enemigo de Prometeo' (Bloch, 1976:1376) del mismo modo que el utopismo es la oposición ante el fatalismo. Esta oposición trasciende la obra de Bloch y por tanto los elementos cristianos que Molnar pueda ver en él son parte de la construcción conceptual que él elabora para explicar un fenómeno que no es solo occidental, sino que tiene sus manifestaciones en todas las culturas, en lo que los Manuel llaman "propensión al utopismo" (Manuel y Manuel, 1997:I). Es verdad que no es casual la elección de Prometeo porque representa también la tecnocracia que busca reemplazar la teocracia. No obstante, como describí más arriba, el pensamiento utópico se adapta a las condiciones sociohistóricas de cada época. Por esta razón, las utopías contemporáneas tienden a ser democráticas, dinámicas y globales y no necesariamente están asociadas con algún tipo de escatología religiosa y mucho menos fatalista, puesto que el mismo fin que buscan realizar es mutable. ${ }^{16}$

\section{La crítica neomarxista de Marcuse}

La relación entre el marxismo y el utopismo siempre fue bivalente. Si bien se puede asociar la crítica a los socialistas utópicos, realizada por Marx y Engels, como una de las primeras de cuño académico al utopismo, es al mismo tiempo esa crítica la que estimuló el estudio de las utopías. Incluso, el marxismo se vio asociado a tal punto con el pensamiento utópico que los términos devinieron afines y generaron confusiones innecesarias. Por eso no extraña que en un pensador neomarxista como Herbert Marcuse esa bipolaridad ante el utopismo se haga manifiesta una vez más. En otras palabras, que un crítico de las utopías sea considerado utópico. Sus obras

Dos ejemplos concretos de utopías contemporáneas son, por un lado, el ciberutopismo que busca la democratización global por medio de la tecnología y la expansión exponencial del alcance de la libertad de expresión, tanto en medios como en número de personas; por el otro, el movimiento transhumanista que busca la buman enhancement 'mejora humana' a partir de la aplicación de mejoras genéticas y técnicas. En ambas se puede pensar una escatología moderna del progreso en lugar de una escatología cristiana de la providencia, como distinguió Löwith (1949). 
El hombre unidimensional y Eros y civilización manifiesta el deseo utópico de una sociedad con un principio de realidad no represivo inspirado en gran parte en la utopía lúdico-estética de Schiller. Sin embargo, en unas conferencias del año 1967 - en el contexto que daría en ebullición al Mayo Francés y en el mismo año que la publicación de Molnar-Marcuse se refiere explícitamente al utopismo de un modo crítico, emulando esa ambigua relación que caracteriza al marxismo desde sus inicios.

Sobre todo, Marcuse considera el carácter de imposibilidad como definitorio del concepto de utopía. Su razonamiento sigue una lógica precisa: si lo que se creía imposible ha devenido posible - esto es, una sociedad regida por un principio de realidad no represivo-, entonces, nos hallamos ante "el final de la utopía". El final está asociado con dos sentidos por momentos contradictorios, uno teleológico (como culminación material) y otro histórico (como caducidad conceptual). En ambos sentidos prevalece la idea un carácter anacrónico de la utopía. Sea lo que sea, una utopía es algo clausurado, encerrado en un tiempo que, para Marcuse, definitivamente ya no es el de nuestra contemporaneidad. Como ambos sentidos se entremezclan en el texto es que hacemos una enumeración de estos.

En primer lugar, se manifiesta un sentido positivo: las utopías son la denuncia de posibilidades sociohistóricas y su final es entendido canónicamente desde el marxismo, ahora sí en un sentido teleológico, puesto que para Marcuse el fin de la historia como un continuum conlleva asimismo el final de la utopía:

Hoy día podemos convertir el mundo en un infierno; como ustedes saben, estamos en el buen camino para conseguirlo. También podemos transformarlo en todo lo contrario. Este final de la utopía - esto es, la refutación de las ideas y las teorías que ha utilizado la utopía como denuncia de posibilidades histórico-sociales- se puede entender ahora, en un sentido muy preciso, como final de la historia, en el sentido, a saber [...] de que las nuevas posibilidades de una sociedad humana y de su mundo circundante no son ya imaginables como continuación de las viejas, no se pueden presentar en el mismo continuo histórico, sino que presuponen una ruptura precisamente con el continuo histórico, presuponen la diferencia cualitativa entre una sociedad libre y las actuales sociedades no-libres, la diferencia que, según Marx, hace de toda la historia transcurrida la prehistoria de la humanidad (Marcuse, 1986:7).

Las nociones contrapuestas de Reino de la Libertad y Reino de la Necesidad de Karl Marx pueden servir como clave hermenéutica para este pasaje. Si se entiende el primer reino como el grado máximo de liberación en el marco de la organización humana, entonces el otro se refiere a la opresión que se ha manifestado a lo largo 
de la historia como dominio del hombre por el hombre y su enajenación creciente. Por consiguiente, la cercanía del Reino de la Libertad remite al de "fin de la historia" en el sentido de una línea de tiempo que tiene como objeto el advenimiento de ese Reino. El utopismo ha desarrollado incontables modelos en los cuales se proyectaron ideales de ese Reino de la Libertad, pero siempre en el marco de una crítica y de una protesta ante la sociedad empírica del autor. La aparición de condiciones que nos permiten hacer de nuestra sociedad lo contrario de un infierno, es decir, un paraíso, es precisamente lo que nos permitiría hablar de fin de la historia y fin de la utopía. Este sería el principio de una nueva era en la que hay una ruptura con el pasado muy marcada que eliminaría la idea del continuum histórico. La enunciación de nuevas posibilidades materiales, ya sea en vías de realización como en instancias de investigación, harían de la mera denuncia utópica una operación fútil. Parafraseando la famosa frase de Marx "no se trata ya de entender el mundo sino de transformarlo" podríamos decir: no se trata de denunciar posibilidades sino de realizarlas.

En segundo lugar, Marcuse entiende la utopía como algo más que una propedéutica científica. La concepción del pensar utópico como pensar precientífico se remonta al escrito de Engels Del socialismo utópico al socialismo científico, de 1876-78, que estableció la falaz dicotomía utopía-ciencia que Marcuse se permite cuestionar. El francfortiano se pregunta si lo que se interpretaba como un pasaje de la imaginación de lo imposible a la racionalidad de lo posible no debería ser invertido y pasar del socialismo científico al socialismo utópico. La utopía toma en el siguiente fragmento el sentido de punto de arribo al reino de la libertad.

el concepto de final de la utopía implica la necesidad de discutir al menos una nueva definición del socialismo, discusión precisamente enmarcada en la pregunta de si la teoría marxiana del socialismo no representa un estadio hoy ya superado del desarrollo de las fuerzas productivas. [...] Creo que una de las nuevas posibilidades, representativa de la diferencia cualitativa entre la sociedad libre y la no-libre, consiste en hallar el reino de la libertad en el reino de la necesidad, en el trabajo y no más allá del trabajo. Si desean ustedes una formulación provocativa de esta idea especulativa, yo diría que hemos de considerar al menos la idea de un camino al socialismo que vaya de la ciencia a la utopía y no, como aún creyó Engels, de la utopía a la ciencia (Marcuse, 1986:8).

Aquí Marcuse propone repensar el socialismo, actualizarlo a las nuevas condiciones del siglo xx. Cuestiona el pasaje de la utopía a la ciencia que describiera Friedrich Engels, primero en el Anti-Dübring y luego en el texto ya mencionado más arriba. En este último Engels sostuvo que el error de los socialistas utópicos-como 
Charles Fourier, Robert Owen o el conde de Saint-Simon - radicaba en creer que para modificar las condiciones de la humanidad entera sería suficiente con establecer un nuevo orden que fuese menos irracional. Engels consideraba que la propia condición de clase burguesa les impidió a aquellos utopistas apercibirse de la necesidad de una transformación más radical. Sin embargo, él consideraba que aún había ideas en sus obras dignas de ser repensadas. Pero esas ideas debían ser filtradas de toda la fantasía y del idealismo, parar garantizar el carácter científico de sus enunciados. Ese filtro era para Engels el materialismo dialéctico.

En cambio, Marcuse, al cuestionar la oposición entre el Reino de la Libertad y el Reino de la Necesidad, aduce que en la nueva mirada al socialismo debería incluirse una nueva perspectiva que las entendiera entrelazadas. No hay Reino de la Libertad sin Reino de la Necesidad, algo que repetirá Hans Jonas posteriormente en su obra El principio de la responsabilidad, 1979. Es por eso que, tal vez con cierta ironía, Marcuse afirma que hay que invertir el proceso y pasar de la ciencia a la utopía. ${ }^{17}$

En tercer lugar, Marcuse resalta dos características centrales del concepto de utopía: historicidad e imposibilidad: "El concepto de utopía es un concepto histórico. Se refiere a los proyectos de transformación social que se consideran imposibles" (Marcuse, 1986:8). Acá hay una aproximación a la utopía bastante precisa por parte de Marcuse, dado que la establece antes que nada como un concepto y como tal, es histórico; esto quiere decir que tiene un origen y que está sujeto a los avatares de la historia. En cierto sentido es a posteriori, no hay un a priori utópico, como podría seguirse de interpretaciones al estilo de Ernst Bloch que se basasen en una tendencia en el hombre a pensar lo que aún no es, previendo como un heroico Prometeo el modo por el cual transformar un panorama social desesperanzador. Marcuse afirma que la utopía se refiere al conjunto de proyectos de transformación social considerados imposibles. Es decir, proyectos sociopolíticos que exceden las posibilidades de los recursos de su tiempo pero que, no obstante, pueden ser factibles en otro momento en tanto que cambian las condiciones de los recursos humanos generando una nueva etapa histórica y, por tanto, una renovación de las utopías. La utopía realizada no es una utopía.

En cuarto lugar, Marcuse critica la ya controvertida concepción de la utopía expuesta por Karl Mannheim en Ideología y utopía, de 1929. Texto que generó múltiples equívocos entre los estudiosos de la utopía y que fue recuperado casi en su

17 Esta idea ya había sido tomada literalmente por Adolfo Sánchez Vázquez en el conjunto de conferencias que componen su libro Del socialismo científico al socialismo utópico, 1975. 
totalidad por el filósofo Paul Ricœur en sus conferencias que llevan el mismo título. Con respecto a Mannheim dice Marcuse:

Creo que solo podemos hablar de utopía en este segundo sentido, o sea, cuando un proyecto de transformación social entra realmente en contradicción con leyes científicas comprobables y comprobadas. Sólo un proyecto así es utópico en sentido estricto, o sea, extrahistórico [...] Los criterios de Karl Mannheim, por ejemplo, son insuficientes para la irrealizabilidad de tales proyectos, por la sencilla razón, por de pronto, de que la irrealizabilidad no se puede definir en este caso más que ex post (Marcuse, 1986:9).

Inmediatamente después de presentar la idea de la utopía como concepto histórico, también sugiere un segundo sentido superador desde el cual la utopía es extrahistórica: es el de proyecto que contradice las leyes científicas. Este sentido subraya el aspecto imaginativo y en cierto modo trascendente de las utopías, muchas veces fruto del ejercicio de la figura retórica del "mundo al revés", según la cual se imagina exactamente lo opuesto a lo que ocurre cayendo en una serie de absurdos. Desde aquí se entiende la "imposibilidad" no como aún-no-posible, sino como imposible por principio, imposible por contradicción. Al mismo tiempo que desliza este otro sentido, critica la concepción de Mannheim de la utopía. Este último, en el marco de la sociología del conocimiento, había dividido las tendencias intelectuales en dos formas primarias: la ideología, entendida como conservación del statu quo y la utopía, como búsqueda de la transformación de ese statu quo. El espíritu utópico para Mannheim no es bueno para hacer diagnósticos en tanto que no ve lo que realmente es, sino lo que debería ser. El espíritu utópico es una suerte de fuerza o tendencia de grupos intelectuales de subvertir un estado de cosas por otro que se considera superior. Esa definición ambigua le permite incluir en la misma clasificación de "utópicos" tanto al marxismo como al liberalismo y al anabaptismo. La irrealizabilidad de los proyectos utópicos que suponen esos intentos de trascendencia del statu quo es indefinible para Marcuse, en tanto que el carácter de irrealizable, según él, solo puede comprenderse luego de haberse intentado. Es por eso que él prefiere el término de imposibilidad y de contradicción en lugar del de irrealizabilidad.

Ya Engels había destacado que no todo en el utopismo era digno de ser dejado a un lado tras el pasaje del socialismo utópico al científico. Marcuse está en la misma línea cuando subraya la labor utópica de uno de los tres socialistas citados por Engels: Charles-Marie-Joseph Fourier. 
Fourier ha sido el primero, como reconocieron Marx y Engels, y también el único en poner de manifiesto esta diferencia cualitativa entre la sociedad libre y la no-libre, sin asustarse, como en parte se asustó Marx, al ponerse a hablar de una sociedad posible en la cual el trabajo fuera juego [... ] Y precisamente porque las posibilidades llamadas utópicas no son en absoluto utópicas, sino negación histórico-social determinada de lo existente, la toma de consciencia de esas posibilidades y la toma de consciencia de las fuerzas que las impiden y las niegan exigen de nosotros una oposición muy realista, muy pragmática (Marcuse, 1970:17-18).

Marcuse vuelve aquí al texto de Engels ya mencionado anteriormente donde se recogen los ejemplos de los denominados "socialistas utópicos". El mote de utópico como puede verse es despreciativo, y que tal vez lo que parece una ironía supone un proyecto concreto: el regreso de la ciencia a la utopía. Hecho que Marcuse realiza en este caso al volver a los criticados, a los socialistas despreciados por no ser científicos, los utópicos. Considerando incluso que Fourier, autor de la idea de los falansterios, de la teoría de los cuatro movimientos y otras ideas originales de asociación y trabajo humanos, tiene un planteo superador: el aspecto lúdico del trabajo. Hacer de esa fuente de enajenación una fuente de libertad. Como la libertad del niño que juega aún en el marco de ciertas reglas - la necesidad-, pero que tiene los suficientes cursos de acción como para ejercer su libertad. Marcuse nuevamente muestra otra cara de la utopía en tanto que lo posible-utópico es pensado como negación de lo histórico-social. Esto se evidencia en teorías como la de Graciela Fernández o de Fernando Aínsa que remarcan el carácter crítico de la utopía como una negación de lo real. Pero en Marcuse esa crítica de lo real es también una suerte de enajenación de lo real y, por tanto, exige un trabajo dialéctico de oposición con una postura pragmático-realista. Es decir, desentraña el peligro que supone negar lo real en pos de un imaginario contradictorio con las condiciones materiales.

En quinto lugar, puede interpretarse otro sentido de utopía dado por Marcuse: utopía como sociedad sin conflictos. Marcuse afirma: "No se trata de una sociedad sin conflictos... ésa sería una idea utópica” (Marcuse, 1986:43). La propuesta del filósofo alemán advierte su propio carácter utópico y, por tanto, la rechaza nuevamente describiendo otra faceta irrealista del utopismo: la armonía. La utopía es entendida de un modo estático, como sociedad perfecta, no como sociedad perfectible. Como fin de la historia, no como progreso continuo. Para Marcuse, la idea de una sociedad utópica implicaría la desaparición del conflicto. Pero la desaparición del conflicto entrañaría también la desaparición de lo humano en tanto que ser polifacético, 
múltiple, con múltiples deseos y necesidades no siempre conciliables dentro del individuo y entre individuos.

En estas conferencias imbuidas del fervor revolucionario que se desataría al año siguiente en el "Mayo Francés", Marcuse brinda una perspectiva compleja de lo que él entiende por utopías. Una utopía es una denuncia de posibilidades histórico-sociales no advertidas u ocultadas ideológicamente. Es el consecuente del cientificismo socialista y no su antecedente. Es un concepto histórico y por tanto sujeto a los avatares del pensamiento humano. No puede medirse por la irrealizabilidad, sino que debe ser pensada a partir de su imposibilidad. Fourier ha sido un utopista ejemplar en cuanto que tuvo el coraje de proponer lo imposible: un trabajo que en lugar de ser enajenador, autorrealice. No obstante, falló al concebir sus falansterios como sociedades sin conflictos. La sociedad sin conflictos como un deseo utópico es el summum de la imposibilidad. Las utopías pasadas han desaparecido, se ha declarado su final en tanto que lo que reclamaban tildado de "imposible" ha devenido posible. A partir de esa posibilidad Marcuse llama a la concreción de la revolución. No puede seguir pensándose en utopías, es tiempo de realizar aquellas que anteriormente eran imposibles. El cambio de las condiciones materiales impele al cambio conceptual. La utopía como concepto histórico no tendría nada que hacer si se declarase el fin de la historia. No hay nada que declarar imposible si ya todo puede ser realizado.

$\mathrm{Al}$ parecer el fervor retórico que teñía esas conferencias menguó en el propio Marcuse en libros posteriores, al reconocer que el fin de la historia es solo un tropo político y que lo imposible sigue en el presente y en el futuro. Se puede leer el texto de Marcuse como el reconocimiento de que una cierta clase de utopías ya ha finalizado y que, probablemente, no vuelvan a repetirse en la historia. Sin embargo, el pensamiento utópico como capacidad humana para pensar proyectos imposibles en el aquí y ahora de quien lo piensa sigue siendo una característica del ser humano a la que ni el propio Marcuse estuvo ajeno.

\section{Conclusiones}

La precisión conceptual en el contexto de la teoría utópica permite desarticular críticas infundadas, ambiguas, confusas o incluso falaces. La distinción entre utopía en particular y pensamiento utópico en general ha sido la herramienta para diferenciar las críticas de tres autores cuyo reconocimiento en otras áreas es innegable; sin embargo, ese prestigio no es extrapolable al estudio de la utopía y por lo tanto no deberían ser tomados como autoridad sobre la materia. Aquí se eligió autores 
que cumpliesen esa doble función, es decir, ser críticos de la utopía y contar con reconocimiento en otras áreas temáticas para mostrar que aun los más destacados pueden producir equívocos cuando los conceptos no son claramente definidos e interpretados con cierta independencia del contexto sociopolítico de su contemporaneidad. Las utopías del siglo $\mathrm{xx}$, sobre todos las de corte socialista, cegaron la capacidad crítica de Popper, Molnar y Marcuse al tentarlos a confundir utopía con pensamiento utópico.

En el caso de Karl Popper, sus intenciones se situaban desde el punto de vista liberal y de la defensa de lo que él denominaba una sociedad abierta frente a las sociedades cerradas a las que se encaminaba el bloque soviético. Popper procuró ir más allá de una mera crítica política buscando bases gnoseológicas para sostener su rechazo del pensamiento utópico, pero sus argumentos más que ligados al conocimiento derivaron en un psicologismo. El razonamiento popperiano podría ser reducido del siguiente modo: fijarse objetivos muy altos frustra, el pensamiento utópico es en sí la fijación de objetivos altos —o últimos—; ergo, el pensamiento utópico es autofrustrante. La honestidad intelectual del filósofo austriaco lo fuerza o ofrecer una contrapropuesta porque reconoce una intentio racional aunque fallida en esa forma de pensamiento de buscar solucionar los problemas que suponen flagelos de la humanidad. No obstante, su propuesta de una ingeniería social fragmentada, de un método del paso a paso, desatiende el carácter urgente de muchos de los desafíos que enfrenta la humanidad y que el hecho de enfocarse en un aspecto mínimo de un problema implica en muchas ocasiones condenar a muerte a generaciones, algo que él mismo aborrece del utopismo. Pensemos en el ejemplo de las condiciones de desigualdad que generan hambruna y pensemos en la aplicación que hacen los organismos internacionales del piecemeal engineering de Popper, mientras se asiste a un grupo muy desfavorecido pero no se solucionan las condiciones de desigualdad de fondo se condena a la próxima generación que de no contar con la asistencia morirá por esas mismas condiciones fijas.

El caso de Molnar, si bien comparte algunos postulados políticos con Popper tiene la particularidad de orientarse en una crítica teológica más que política. La motivación política está y el enemigo sigue siendo el bloque soviético, cuyo ateísmo es manifiesto y militante. Algo intolerable para un creyente ortodoxo convencido de que su religión es la verdad y el bien supremo se encuentra en una vida ulterior. Obviando la evaluación de la veracidad o no de esos postulados por respeto a los creyentes y porque un tema de esta índole excede las posibilidades de este trabajo, se puede analizar filosóficamente el razonamiento de Molnar. Para él el pensamiento utópico es herético porque diviniza al ser humano y seculariza la idea de paraíso, lo 
cual no sería per se negativo si no fuera en detrimento del poder divino y de la fuerza persuasiva del paraíso celestial. Podría decirse que Molnar comprende mejor que Popper la función del pensamiento utópico al asumirlo como una revalorización de las capacidades humanas y de las posibilidades de mejora social concretas y terrenales. Sin embargo, de ese deseo de una mejora terrenal no se sigue necesariamente una desvalorización del carácter supremo del poder divino ni del carácter insuperable del paraíso celestial como fin supremo. Ha habido menos utopías ateas que utopías creyentes, es cierto que la idea de paraíso terrenal como preparación para el celestial ha sido frecuente en destacados pensadores protestantes (Bacon, Comenio), pero también ha sido defendida por autores católicos, quienes interpretan el cristianismo primitivo como una forma de utopismo (Iraburu, 1998) y por teólogos protestantes que ven en el utopismo una oportunidad y no un enemigo para el cristianismo (Vahanian, 1977; Tillich, 1982).

Por último, el caso de Marcuse es más complejo porque su crítica no parece originarse en el pesimismo como ocurre con Popper y Molnar, sino todo lo contrario, en un gran optimismo en las capacidades humanas para establecer un principio de realidad no represivo y para la consecución material de las utopías soñadas tiempo atrás. Para Marcuse la caducidad de la utopía viene de su conversión en topía, es decir, en realidad, en proyecto realizable. El problema está en que la concepción de utopía que tiene Marcuse es de irrealizabilidad, mientras que otros autores, que leyeron mejor a Moro, como posibilidad (Bloch, Manuel, Moylan, etcétera). Si se intercambian estas dos interpretaciones y se piensa nuevamente la noción de pensamiento utópico este se convierte en una constante búsqueda de mejoras sociales, de ver qué cosas aún no se realizaron independientemente de que en un tiempo anterior fueran consideradas posibles o imposibles. Lo interesante de Marcuse es su crítica de Mannheim, porque la ambigua definición del filósofo húngaro había traído mucha oscuridad al concepto de utopía.

Las tres críticas confunden, cada una a su manera, a las utopías particulares que están sujetas al espíritu de un tiempo, a ciertos condicionamientos sociohistóricos e incluso científicos - con el pensamiento utópico. Este último es un método de mejoramiento social a partir de una crítica creativa, constante y autocrítica, sostenida a partir de un discurso que se opone a lo aparentemente "fatal" — establecido por la ideología de una época- y que pone énfasis en la capacidad transformadora de la humanidad. Los aportes de estos autores, aun cuando injustos para con la teoría de la utopía, contribuyen a la generación de un desafío para que esta área de estudios defina con mayor precisión el alcance de ciertos conceptos, de modo que el objetivo de mejora social incluya también el de la conciencia histórica de esa mejora. El siglo 
XXI está viendo un renacer del pensamiento utópico con nuevas posibilidades materiales como las que advertía Marcuse; no obstante, muchos problemas ligados a la desigual distribución de las oportunidades y los recursos son idénticos a aquellos que motivaron a los pensadores antiguos y premodernos a proyectar sus utopías. El desafío actual radica en ser conscientes de nuestras limitaciones contemporáneas, pero al mismo tiempo ser capaces de preparar el terreno para el porvenir, intentando acercar ese futuro a los problemas que nos aquejan como humanidad de modo novedoso y también de modo continuo. Estos últimos problemas tal vez no desaparecerán por completo pero pueden variar en su alcance y sobre todas las cosas, en el daño que nos generen o que permitamos que nos generen.

\section{Bibliografía}

Aínsa, Fernando (1999), La reconstrucción de la utopía, Del Sol, Buenos Aires. Apel, Karl-Otto (1986), “'Es la ética de la comunidad ideal de comunicación una utopía?, en Estudios éticos, trad. C. de Santiago, Alfa, Barcelona. Benhabib, Seyla (1986), "A Study of the Foundations of Critical Theory", en Critique, Norm and Utopia, Columbia University Press, Nueva York. Berlin, Isaiah (1986), "Two Concepts of Liberty", en Four Essays on Liberty, Oxford University Press, Oxford.

Bloch, Ernst (1976), Das Prinzip Hoffnung, Suhrkamp Verlag, Fráncfort.

(1988), The Utopian Function of Art and Literature, міт Press, Cambridge. Campanella, Tommaso (1954), Tutte le opere, ed. crít. de L. Firpo, vol. I, Mondadori, Verona.

Cioranescu, Alexandru (1972), L’Avenir du Passé: Utopie et littérature, Gallimard, París.

Comparato, Vittor Ivo (2006), Utopía, Nueva Visión, Buenos Aires (Colección Léxico de Política.

Davis, James Colin (1985), Utopía y la sociedad ideal, Fondo de Cultura Económica, México.

Fernández, Graciela (2005), Utopía, Suárez, Mar del Plata.

Habermas, Jürgen (20I0), "El concepto de dignidad humana y la utopía realista de los derechos humanos", Diánoia, Lv(64), mayo, pp. 3-25.

Iraburu, José María (1998), Evangelio y utopía, Gratis Date, Pamplona. Jonas, Hans (1995), El principio de responsabilidad, trad. A. Sánchez Pascual, Herder, Barcelona. 
Kateb, George (1982), "La utopía y la buena vida”, en F. E. Manuel (comp.), Utopía y pensamiento utópico, Espasa, Madrid, p. 292.

Kumar, Krishan (1990), "Wells and the 'So-Called Science of Sociology", en Patrick Parrinder y Christopher Rolfe, H.G. Wells under Revision. Proceedings of the International H.G. Wells Symposium, London, July 1986. Associated University Press, Londres, pp. 192-217.

Löwith, Karl (1949), Meaning in History, University of Chicago Press, Londres. Mannheim, Karl (1966), Ideología y utopía, Aguilar, Madrid.

Manuel, Frank E. y Fritzie P. Manuel (1997), Utopia Thought in the Western World, Belknap Press, Cambridge, Massachussetts,.

Marcuse, Herbert (1986), El final de la utopía, Seix Barral, Barcelona.

Molnar, Thomas (1970), El utopismo: la herejía perenne, trad. Motel Najszatan, Eudeba, Buenos Aires.

Moylan, Tom (2000), Scraps of the Untainted Sky, Science Fiction, Utopia, Dystopia, Westview Press, Boulder, Colorado.

Moreau, Pierre-François (1986), La utopia: derecho natural y novela del Estado, trad. I. Cuña de Silberstein, Hachette, Buenos Aires.

Moro, Tomás (193I), The English Works of Sir Thomas More, vol. I, Eyre and Spottiswoode, Londres.

Nozick, Robert (199I), Anarquía, Estado y Utopía, trad. R. Tamayo, FCE, Buenos Aires.

Orwell, George (1946), "Wells, Hitler and the World State", en Critical Essays, Morrison \& Gibb, Londres/Edimburgo, pp. 83-88.

Paden, Roger (2000), "Popper's Anti-utopianism and the Concept of an Open Society", The Journal of Value Inquiry, 34, Kluwer Academic, Holanda, p. 409.

Pico della Mirandola, Giovanni (2008), Discurso sobre la dignidad del hombre, trad. y est. introd. de S. Magnavacca, Winograd, Buenos Aires.

Popper, Karl (199I), Conjeturas y refutaciones, Paidós, Barcelona.

Roig, Arturo Andrés (1987), Utopías en el Ecuador, Corporación Editora Nacional, Quito.

Tillich, Paul (1982), “Crítica y justificación de la utopía”, en F. E. Manuel (comp.), Utopia y pensamiento utópico, Espasa, Madrid.

Trousson, Raymond (1995), Historia de la literatura utópica, Península, Barcelona. Vahanian, Gabriel (1977), Dieu et l'Utopie, Editions du Cerf, París.

Wells, H. G. (200o), Una utopía moderna, trad. J. Sánchez Rottner, Océano, México. 